\title{
A quality improvement project to improve diabetes self-management and patient satisfaction in a low-resourced central Kenyan hospital
}

Tsitsi Muhoma, Margaret W Waruiru, Olayemi Sanni, Linda D Knecht, Marilyn McFarland.

University of Michigan - Flint, School of Nursing.

\section{Author details:}

Tsitsi Muhoma, Doctor of Nursing Practice, tmuhoma@gmail.com Margaret W Waruiru, Doctor of Nursing Practice student, mwaruiru@umich.edu

Olayemi Sanni, Doctor of Nursing Practice student, osanni@umich.edu

Linda D. Knecht, Clinical Associate Professor, lknecht@umich.edu

Marilyn McFarland, Professor, mmcf@umich.edu

\begin{abstract}
Background: There is limited evidence about effective strategies for promoting culturally congruent diabetes education in low-resourced primary-care settings.

Objectives: This project, conducted in Central Kenya, examined the effect of an intervention on provider practices and patients' knowledge of diabetes self-care management.

Methods: The intervention consisted of short (30-minute) sessions that offered providers evidenced-based, culturally congruent diabetes education and teaching materials to use with patients. A checklist was used to assess providers' diabetes care practices at baseline and post intervention. Data from semi-structured patient interviews assessed patients' diabetes knowledge at baseline and post intervention. Providers and patients also completed post-intervention satisfaction surveys.

Results: Six providers and 74 patients participated in the project. Statistical analysis was completed using SPSS. Significant increases were noted in patients' post-intervention overall diabetes knowledge score $(p=.05)$ and the foot care knowledge subscale $(\mathrm{p}=.02)$. No significant differences were noted between patients' baseline and post-intervention scores in the general diabetes $(\mathrm{p}=.86)$ or nutrition knowledge $(\mathrm{p}=.32)$ subscales.

Conclusion: These findings suggest supporting providers with culturally congruent tools and resources about diabetes care guidelines can improve knowledge of self-care practices in patients with diabetes.

Keywords: Type II diabetes mellitus, foot care, diabetes self-care, diabetes education, culturally congruent, Swahili, Kikuyu, central Kenya.

DOI: https://dx.doi.org/10.4314/ahs.v20i3.38

Cite as: Muboma T, Waruiru MW, Sanni O, Knecht LD, McFarland M. A quality improvement project to improve diabetes self-management and patient satisfaction in a low-resourced central Kenyan hospital. Afri Health Sci. 2020;20(3): 1322-1328. bttps:// dx.doi.org/10.4314/abs.v20i3.38
\end{abstract}

\section{Corresponding author:}

Margaret W Waruiru

University of Michigan - Flint

School of Nursing

2180 William S. White Building

Flint, Michigan, USA,

Zip Code 48502-1950

Email: mwaruiru@umich.edu

\section{Introduction}

Diabetes, once considered a disease of affluent societies, is now a growing problem in middle and low-income countries, largely due to obesity. ${ }^{1}$ In 2012 , more than $80 \%$ of the 15 million global diabetes-related deaths occurred in low-income and developing countries. $^{2}$ In Africa, the number of people diagnosed with diabetes is projected to reach 18.6 million by $2030 .^{3}$ Unfortunately, as the diabetes prevalence rises, so will the incidence of disease complications. By 2035, it is estimated that of the 600 million people with diabe- 
tes worldwide, $50 \%$ will develop peripheral neuropathy and $15-25 \%$ will have at least one foot ulcer. ${ }^{4}$ Diabetes prevalence in the developing, low-resourced country of Kenya is estimated at $4.2 \%$ of the general population (2.2-2.7\% in rural areas, $10.7-12.2 \%$ in urban areas). ${ }^{5,6}$ While it is challenging to secure accurate diabetes prevalence data in Kenya, the consensus is that there is an alarming increase in this condition. ${ }^{6,7}$ Additionally, diabetes has a significant impact in Kenya, with $1 \%$ of all deaths directly related to diabetes, and Type II diabetes responsible for $69.9 \%$ of vascular amputations and $11.4 \%$ of all amputations. ${ }^{2,8}$ To address the worldwide diabetes problem, healthcare professionals and stakeholders must collaborate to provide education, health-promotion programs, treatment, and care at the primary healthcare level. ${ }^{9}$ Providing effective care for patients requires addressing not only their illness but also their cultures, priorities, and lifestyles. While culturally appropriate education on diabetes self-care can help increase positive patient outcomes,${ }^{10}$ there is limited evidence about effective strategies for promoting culturally congruent diabetes education in low-resourced primary care settings. Therefore, this quality improvement project was designed to promote the integration of upto-date, evidence-based diabetes education guidelines through culturally congruent provider education sessions and teaching materials that acknowledge patients' cultural, socioeconomic, education, technological, and psychosocial factors. The intervention's effectiveness was determined by measuring provider practice changes and patients' diabetes knowledge and care satisfaction.

\section{Methods}

\section{Setting and Participants}

This project was conducted in an out-patient diabetes clinic at a low-resourced district hospital in central Kenya, which sees 25-30 patients daily. Healthcare providers and patients were recruited by convenience sampling, informed of the project, and asked to participate on a voluntary basis. Inclusion criteria were persons with type II diabetes who were over age 16. Persons with Type I diabetes were excluded from the study.

Patients attended a one hour diabetes group education session (conducted by nurse educators, nutritionists, or clinical officers) on their scheduled appointment day after which they had individual consultations with a provider (physician or clinical officer).

Regular group sessions included few educational posters on the clinic wall but did not include any take home education materials.

\section{Design}

A quasi-experimental design with qualitative elements was used to assess provider practices, patient knowledge, and care satisfaction at two time points: the week before and the week after the intervention. The week before was considered the baseline for this project. The research project (HUM00146750) received a not regulated determination from the university and was approved by the hospital.

The 30-minute interactive educational session for providers included up-to-date practice recommendations on diabetes care according to the Kenya Diabetes Management Information Centre (KDMIC), ${ }^{6}$ Kenya National Diabetes Educators Manual (KNDEM), ${ }^{11}$ and the World Diabetes Foundation. ${ }^{12}$ Three topics were addressed: diabetes nutrition (healthy plate), foot care, and management/complications. Providers were given and guided on the use of posters covering the three topics. The providers also received pamphlets to give to patients during teaching sessions. The posters and pamphlets included culturally congruent pictures and text in three languages: English, Swahili, and Kikuyu. Providers were encouraged to determine patients' preferred language and use the corresponding educational materials.

\section{Tools}

A needs assessment at the clinic was done four months prior to the start of the study. All the tools and education materials were developed after the needs assessment, with a goal of addressing important components of diabetes self-management and filling deficient education areas in a culturally congruent manner. The educational materials were then reviewed by the hospital superintendent for areas of need, language and cultural relevance and approved prior to the implementation phase. All five researcher-created tools were based on KDMIC, ${ }^{6} \mathrm{KNDEM}^{11}$ and World Diabetes Foundation $^{12}$ guidelines: provider education session checklist (baseline and post intervention), provider satisfaction survey (post intervention), patient demographic survey (baseline and post intervention), patient education assessment tool (baseline and post intervention), and patient satisfaction survey (post intervention).

Provider tools. Providers' interactions with patients were observed using the 18-item provider education session checklist to determine if they included the three topics in their teaching practice. Each item was scored yes or no according to whether or not it was addressed. The eight-item provider satisfaction survey assessed the 
trainings' usefulness, the teaching resources' ease of use, and providers' satisfaction with the intervention.

\section{Patient tools.}

The 15-item demographic survey included questions about the patient, their family, and their experiences living with diabetes. The 13-question diabetes knowledge assessment tool was divided into three subscales: general diabetes knowledge (four questions), diabetes nutrition knowledge (five questions), and diabetes foot care knowledge (four questions).

The researchers tabulated an overall score and subscale scores for each patient at baseline and post intervention. Both this tool and the patient demographic survey were administered during semi-structured, one-on-one interviews with the researchers.

The six-item patient satisfaction tool was an open-ended survey designed to assess patients' satisfaction with the education they received. Patient data were routinely obtained verbally. Depending on patient preference, the researchers conducted the surveys in Kikuyu, Swahili, or English. An interpreter was available as needed.

\section{Data analysis}

Interview data in Kikuyu or Swahili were translated into English. Discrepancies were resolved during discussions among the researchers. Analysis was completed using descriptive statistics and inferential statistics (chi square analysis, independent t-tests, and Mann Whitney $\mathrm{U}$ analysis) using the Statistical Package for the Social Science (SPSS) version 2.5.

\section{Results}

The clinic employed six healthcare providers for the education of the patients routinely. All six healthcare providers participated in the education sessions. Seventy-eight patients volunteered to participate in the project. Three incomplete and one type I diabetes interviews were discarded leaving 74 patients (38 in baseline group, 36 in post-intervention group) for analysis.

Table 1. Overall Diabetes Knowledge Total and Subscale Scores for Patients at Pre Intervention $(n=38)$ and Post Intervention $(n=36)$

\begin{tabular}{|l|l|l|l|}
\hline & $\begin{array}{c}\text { Pre } \\
\text { Intervention }\end{array}$ & $\begin{array}{c}\text { Post } \\
\text { Intervention }\end{array}$ & \multirow{2}{*}{ P value } \\
\cline { 1 - 3 } Subscale & M(SD) & M(SD) & \\
\hline General Diabetes Knowledge & $7.13(1.28)$ & $7.08(1.13)$ & 0.86 \\
\hline Diabetes Nutrition Knowledge & $10.82(2.34)$ & $11.42(2.78)$ & 0.32 \\
\hline Diabetes Foot Care Knowledge & $9.42(2.25)$ & $10.72(2.50)$ & 0.02 \\
\hline Total/Overall Diabetes Knowledge & $27.37(3.89)$ & $29.22(4.27)$ & 0.05 \\
\hline
\end{tabular}

M: mean, SD: Standard Deviation

\section{Provider Care Practice Outcomes}

Due to the small sample size (six), all provider data were analyzed descriptively. Providers increased their frequency of educating patients on drying well between toes, keeping skin smooth, wearing proper footwear, and avoiding walking barefoot from $60 \%$ during baseline to $100 \%$ post intervention. In addition, education on trimming toenails, wearing soft socks, and addressing diabetes complications significantly improved from $40 \%$ during baseline to $100 \%$ post intervention. Covering the topic of avoiding tight socks improved from $20 \%$ at baseline to $100 \%$ post intervention. The dangers of overeating often were not addressed either at base- line $(<20 \%)$ or post intervention $(<25 \%)$. Frequency of education on portion control, meal planning, balanced diet, and overeating avoidance decreased from $100 \%$ at baseline to $75 \%$ post intervention. Providers did not address smoking cessation or provide dietician referrals at baseline or post intervention.

\section{Patient outcomes}

Demographics. The baseline group had 15 males and 23 females; the post-intervention group had 11 males and 25 females. Patients' ages ranged from 17-89 years at baseline and 28-85 years at post intervention, with a mean age and standard deviation of 56.6 years (14.3) 
and 59.4 years (13.7), respectively. There was no significant difference in the number of years patients had been diagnosed with diabetes ( 8.0 baseline; 6.6 post intervention), high school education levels ( $43 \%$ females and $47 \%$ males at baseline; $35 \%$ females and $36 \%$ males post intervention), or marital status ( $82 \%$ married at baseline; 70\% married at post intervention). Patients' in both groups had similar occupations: farmer, homemaker, artisan, business person, or retired. Overall, 46\% of the patients spoke Kikuyu, Swahili, and English; $31.1 \%$ Kikuyu and Swahili; and $20.3 \%$ only Kikuyu. Almost half the patients in both groups reported having difficulty buying their medications.

In both groups, more than $45 \%$ of patients had first-generation family members diagnosed with diabetes. Overall, health status was rated as good or excellent by $57 \%$ of females and $33 \%$ of males in the baseline group, and by $27 \%$ of females and $55 \%$ of the males in post-intervention group. No differences in quality-of-life ratings were noted between groups. Patients in both groups $(>94.5 \%)$ reported receiving diabetes information during education sessions in the clinic. Other reported television or radio as other information sources.

Using an alpha level of .05, the overall change in total diabetes knowledge scores was statistically higher $(p=.05)$ (Table 1), with the post-intervention group's mean score higher than baseline.
General diabetes knowledge. No significant difference was noted between the pre- and post-intervention groups in the general diabetes knowledge subscale score $(\mathrm{p}=.86)$. Patients in both groups described controlling diabetes by managing diet, taking medications, and reducing stress.

Most patients (100\% at baseline; $94.4 \%$ post intervention) could name at least one diabetes complication.

Diabetes nutrition knowledge. No significant difference was noted between groups in diabetes nutrition knowledge $(\mathrm{p}=.32)$. Patients in both groups consistently described a direct relationship between diet and diabetes control.

Diabetes foot care knowledge. There was a statistically significant increase in two post-intervention foot care knowledge subscale scores $(\mathrm{p}=.02)$ (Table 1): "Can you explain why caring for your feet is important?” $(p=.02)$, and "Based on your knowledge of diabetes, describe how you manage foot complications?" $(\mathrm{p}=.01)$ (Table 2). Patients' primary foot care strategies were washing and drying feet and wearing comfortable shoes. Most patients in both groups mentioned non-healing wounds or amputation as possible complications of inadequate foot care.

\section{Project Satisfaction Indicators}

The survey indicated 100\% provider satisfaction with the intervention. Providers especially appreciated the posters' organized layout and the availability of pamphlets for patients. 
Table 2. Individual Diabetes Knowledge Questions Score Means

\begin{tabular}{|c|c|c|c|c|}
\hline & Diabetes Knowledge Question & $\begin{array}{l}\text { Mann- } \\
\text { Whitney } \\
\text { U }\end{array}$ & $\mathbf{Z}$ & $\begin{array}{c}\mathbf{P} \\
\text { value }\end{array}$ \\
\hline \multirow{4}{*}{$\begin{array}{l}\text { General } \\
\text { Diabetes } \\
\text { knowledge }\end{array}$} & Can you describe how to control and manage DM? & 681.000 & -0.048 & 0.962 \\
\hline & Can you describe to me the complications of diabetes? & 621.500 & -0.759 & 0.448 \\
\hline & What do you believe causes diabetes? & 622.000 & -1.047 & 0.295 \\
\hline & $\begin{array}{l}\text { What is your understanding of measures of preventing } \\
\text { diabetes? }\end{array}$ & 679.000 & -0.091 & 0.927 \\
\hline \multirow{5}{*}{$\begin{array}{l}\text { Diabetes } \\
\text { Nutrition } \\
\text { knowledge }\end{array}$} & What is your understanding of diabetes and diet? & 670.500 & -0.155 & 0.877 \\
\hline & $\begin{array}{l}\text { What is your understanding of food choices used to } \\
\text { manage diabetes? }\end{array}$ & 628.000 & -0.628 & 0.530 \\
\hline & $\begin{array}{l}\text { Based on your knowledge of diabetes, can you give } \\
\text { examples of foods recommended for diabetes } \\
\text { management? }\end{array}$ & 615.500 & -0.178 & 0.859 \\
\hline & $\begin{array}{l}\text { Based on your knowledge of diabetes, what foods should } \\
\text { you avoid? }\end{array}$ & 595.000 & -1.055 & 0.291 \\
\hline & Describe to me how to plan your meals & 555.500 & -1.120 & 0.263 \\
\hline \multirow{4}{*}{$\begin{array}{l}\text { Diabetes } \\
\text { Foot Care } \\
\text { Knowledge }\end{array}$} & Can you explain why caring for your feet is important? & 419.000 & -3.068 & $* 0.002$ \\
\hline & $\begin{array}{l}\text { Based on your knowledge of diabetes, tell me how you } \\
\text { take care of your feet. }\end{array}$ & 661.500 & -0.057 & 0.955 \\
\hline & $\begin{array}{l}\text { Based on your knowledge of diabetes, describe how you } \\
\text { manage foot complications }\end{array}$ & 477.500 & -2.540 & $* 0.011$ \\
\hline & $\begin{array}{l}\text { Based on your knowledge of diabetes Describe how you } \\
\text { deal with any problems with your feet in the future }\end{array}$ & 648.000 & -0.452 & 0.652 \\
\hline
\end{tabular}

The educational intervention success was evidenced by providers' consistent delivery of diabetes education to patients. Providers offered several recommendations for improving diabetes management including educating the community, focusing on hypoglycemia, acquiring foot assessment equipment, using more visuals, and pamphlets/posters on other topics in local languages. At the end of the post intervention, patients' satisfaction survey was obtained, with a $100 \%$ satisfaction result. All patients interviewed found the intervention helpful in creating meal plans, and felt the written materials and handouts had a good balance of instruction and visuals.

\section{Discussion}

Overall, there were no statistically significant improvements observed in the areas of general diabetes care and nutrition teachings between baseline and post intervention. This finding may be related to the likelihood that these topics were already integrated into provider practices.

However, providers were not addressing foot care to the degree that was expected to meet up-to-date guidelines. After having an educational session that included a foot care focus and receiving culturally congruent posters/ pamphlets, the providers added foot care information to their educational sessions with patients. Interestingly, some areas of nutritional teaching decreased post intervention. It is unknown if this finding was due to providers focusing on foot care instead of nutrition during the limited time they had with patients. Additionally, providers were not observed teaching about smoking risks and cessation as beneficial at baseline or post intervention.

Providers and patients both stated a desire for culturally congruent diabetes educational materials. Providers also expressed a commitment to sustain the project by using the provided posters and pamphlets, and incorporating 
foot care education in their practices. Some patients requested spousal education, more pamphlets, and videos to address challenges related to family members who did not understand the disease. Although there was a $25 \%$ drop in the providers' nutrition teaching in the post intervention, overall, there was success in the area of foot care management with a $100 \%$ post intervention. This $25 \%$ drop in nutrition education maybe as a result of the providers focusing more on the foot care management and less on nutrition education during post intervention. All the baseline educational material on the clinic walls was related to nutrition. The availability of educational material that focused on another aspect of management of type two diabetes could have led to a decrease in the frequency of education on portion control, meal planning, balanced diet, and overeating avoidance. Overall, the use of culturally congruent posters and pamphlets supported effective care provision in a low-resourced setting and increased both the providers and patients' care satisfaction.

The combination of both nutrition and foot care management education in the training session may have impacted the overall outcome of the diabetes education project. This is evidenced by the $25 \%$ drop in provider nutrition teaching and a $100 \%$ foot care teaching post intervention. It may be recommended for a future project not to combine several teaching tools, to avoid the need of the providers picking a particular one over the other.

\section{Limitations}

The use of convenience sampling, small sample size, short time frame, and only one setting. These factors result in a limited transferability of these findings.

For future development, this project could be replicated in similar, larger settings over a longer period to obtain data that are more robust. The knowledge that the providers were being evaluated could have created a bias on how they taught during the baseline and intervention phases. Since this was a culturally relevant project, bias was not considered a liability. Rather, the researchers and participants were internationally transparent and this prior knowledge was considered enriching, rather than distracting from the project. Therefore, there was less emphasis on mitigating bias and more emphasis on collaboration and the impact of the results. This project's main practice implications is the knowledge that providing educational materials that are responsive to patient preferences can enhance knowledge and may help improve health outcomes of diabetes patients' in low-resourced settings.

\section{Conclusion}

A needs assessment of the hospital under study revealed a lack of updated diabetes education. Diabetes educators in the low-resourced clinic setting confirmed they lacked tools to help their patients understand the disease process. The need was supported by Kenyan literature advocating changes in how diabetes should be managed in Kenya. ${ }^{10,11}$ This project's findings suggest that using short education sessions to update and educate providers about evidenced-based diabetes care guidelines and supplying culturally congruent educational resources can alter provider practices and improve patients' diabetes knowledge and satisfaction with care in low-resourced settings.

\section{Conflict of interest}

None declared.

\section{References}

1. World Health Organization. Diabetes. WHO website. https://www.who.int/diabetes/en/. Accessed July 1, 2019.

2. World Health Organization. Kenya faces rising burden of diabetes. WHO website. http://www.who.int/ features/2014/kenya-rising-diabetes/en/.Updated November 2014. Accessed July 1, 2019.

3. Azevedo M, Alla S. Diabetes in sub-Saharan Africa: Kenya, Mali, Mozambique, Nigeria, South Africa and Zambia. Int J Diabetes Dev Ctries. 2008 Oct;28(4):101-8. doi:10.4103/0973-3930.45268

4. Bus SA, van Netten JJ. A shift in priority in diabetic foot care and research: $75 \%$ of foot ulcers are preventable. Diabetes Metab Res Rev. 2016 Jan;32 Suppl 1:195200. https://doi.org/10.1002/dmrr.2738

5. Wambui Charity K, Kumar AM, Hinderaker SG, Chinnakali P, Pastakia SD, Kamano J. Do diabetes mellitus patients adhere to self-monitoring of blood glucose (SMBG) and is this associated with glycemic control? Experiences from a SMBG program in western Kenya. Diabetes Res Clin Pract. 2016 Feb;112:37-43. https://doi. org/10.1016/j.diabres.2015.11.006

15

6. Kenya Diabetes Management \& Information Centre. Diabetes fact file. http://dmi.or.ke/index.php/diabetes/. Accessed July 1, 2019.

7. Ayah R, Joshi MD, Wanjiru R, Njau EK, Otieno CF, Njeru EK, et al. A population-based survey of prevalence of diabetes and correlates in an urban slum community in Nairobi, Kenya. BMC Public Health. 2013 Apr;13(1):371-371.https://doi.org/10.1186/14712458-13-371 
8. Ogeng'o JA, Obimbo MM, King'ori J. Pattern of limb amputation in a Kenyan rural hospital. Int Orthop. 2009 Oct;33(5):1449-53. https://doi.org/10.1007/ s00264-009-0810-5

9. Powers MA, Bardsley J, Cypress M, Duker P, Funnell MM, Hess Fischl A, et al. Diabetes Self-management Education and Support in Type 2 Diabetes: A Joint Position Statement of the American Diabetes Association, the American Association of Diabetes Educators, and the Academy of Nutrition and Dietetics. Diabetes Care. 2015Jul;38(7):1372-82. https://doi.org/10.2337/dc150730

10. Pastakia SD, Karwa R, Kahn CB, Nyabundi JS. The evolution of diabetes care in the rural, resource-con- strained setting of western Kenya. Ann Pharmacother. 2011 Jun;45(6):721-6. https://doi.org/10.1345/ aph.1P779

11. Republic of Kenya, Ministry of Public Health and Sanitation. Kenya National Diabetes Educators Manual. Nairobi, Kenya: Ministry of Public Health and Sanitation; 2010. Available at https://www.worlddiabetesfoundation.org/sites/default/files/Kenya $\% 20 \mathrm{Na}$ tional $\% 20$ Diabetes $\% 20$ Educators $\% 20$ Manual.pdf 12. World Diabetes Foundation. Kenya launches Africa's first national diabetes strategy. WDF website. https://www.worlddiabetesfoundation.org/news/kenya-launches-africas-first-national-diabetes-strate 